\title{
Foreword to the new edition
}

In the thirty-odd years since it was published, there has been no new edition of this book; ${ }^{1}$ and it has long been out of print. To reissue it now, with the main text unchanged and with only this short foreword, may seem a presumptuous decision. I should first attempt to justify that decision. The book appeared near the outset of a pronounced re-orientation of attitudes in the archaeology of the English-speaking countries, and was in some respects typical of this new orientation. The search for an archaeology of process, which could construct a narrative that was independent, deriving neither from historical analogy, nor from the scanty documentary sources that could be brought to bear on such a period as that covered by this book, was then being conducted on every side. In purely prehistoric contexts, this took the form of the movement labelled 'New Archaeology' - a movement which pursued these goals much further, but whose heyday is now past. But the larger purpose of the reorientation is still very much alive today: the insistence that archaeological material can be used to explain change as well as to describe it; above all, that the rise and decline of cultures needs to be interpreted without that persistent recourse to a narrative of conquests and borrowings which characterised the archaeology of the preceding two hundred years and more. If the book is still consulted today, it is precisely because these tenets are not obsolete.

The book also stood at the beginning of a much more localised phenomenon: the exponential increase in study and field-work directed to the, hitherto neglected, period of Greece's past with which it dealt. This change is in one sense gratifying; but it is also one reason why, today, I find it an insur- 
mountable task to try to produce an updated edition, which could make a claim to anything approaching comprehensiveness. The numbers of published sites, buildings, graves and sanctuary-deposits which are now available for consideration in a synthetic study of this period must have increased between five- and ten-fold since 1971. This order of increase is perhaps not entirely out of line with that in other archaeological fields, within and beyond the Greek and Mediterranean worlds; but it would make it a difficult task to embark on writing afresh such a synthesis today - and positively intimidating to think of doing so within a framework adopted for that selection of the evidence which happened to be available thirty years ago. ${ }^{2}$

This prompts the immediate question: is that framework then obsolete? Here, one may begin with my choice of title, incorporating the phrase 'The dark age'. Despite the fact that I still strongly maintain the position implied by that phrase, I nevertheless regret not having named the book, say, The Early Iron Age of Greece. For one thing, such an alternative title would have underlined one message of the book (Chapter 5), that in the case of Greece (unlike those of many other cultures in later prehistory) the 'Iron Age' is not a mere convenience-label, but actually means what it suggests - a cultural epoch in which iron had become the main metal for practical use. But, more importantly, it would have avoided presenting such a tempting target for the attempts to use later discoveries to dilute, modify, or reject outright ${ }^{3}$ the view that a prolonged period of cultural, economic and social regression had engulfed Greece after the fall of the Mycenaean civilisation. Today, not a year passes without a claim that some new find, or some newly revealed evidence of continuity, has invalidated the belief in such a period of 'darkness'. Yet it remains beyond question that the material picture presented by this period is still generally devoid of many of those important attributes which can be found in the record of both the preceding and, still more obviously, the ensuing ages.

A more interesting question, not often enough addressed directly, is whether, despite the modesty of these physical traces, Greek society nevertheless retained many of the archaeologically invisible institutions, practices and aspirations of the Mycenaean age, or anticipated those whose existence is confirmed by later historical records. Even if it were shown to have done so, however, explanations on a profound level would still be needed to account for this drastic impoverishment in the archaeological record; 
above all, for the quantitative impoverishment which, along with others, I attribute primarily to depopulation. Here, nothing in the past three decades has served to bring about a change in this quantitative picture, relative to the periods before and after, except to reinforce it. Further, the geographical concentration of the new finds, as of the old, serves to underline the disparity between those regions of Greece which possessed an Aegean seaboard, and those which did not (the 'advanced' and 'backward' regions of Chapter 7, pp. 374-6, but with the former now emphatically joined by Euboea, on the strength of the remarkable finds since published from Lefkandi and elsewhere). ${ }^{4}$

Perhaps the least-cited chapter of the book has been the first, in which the evidence of literature and epigraphy is used to demonstrate that the explicit concept of a 'dark age' was unknown to the Greeks of historical times, and is essentially a finding of early twentieth-century scholarship: only the implicit argument, from the silence and apparent ignorance of the Greeks of any names or episodes which we would date between the eleventh and the eighth centuries, can be cited as ancient support for this modern construct. Yet only a 'neo-fundamentalist' view, of the kind that has begun to re-emerge since the appearance of the first volume of Martin Bernal's Black Athena in 1987, would maintain that Greek archaeology (and other branches of scholarship) should be primarily constrained by the testimony of Greek literature, and contradict it at their peril; a modern discipline, in my view, is by definition one that does not tolerate the imposition of such a strait-jacket. In this chapter, as is to be expected with a topic centred on written evidence, there is less need for urgent updating than in any other part of the book, with the exception of a passage on the evidence for the Phoenicians in the west (p. 18) which is now seriously defective and outdated.

With the chapters on the pottery series (2) and on chronology (3), a new edition would have contained much new material, but only a handful of cases where the account would have been substantially rewritten. These latter would include Euboea, Phokis and Lokris (pp. 7I-3), where entire ceramic sequences have been filled in, rather than merely reinforced at points already attested; and Thrace and the northern Aegean (p. 90), where a pottery series linked at many points with that of the central regions of Greece has recently emerged. As a result of these and other advances, the list of regional pottery styles has been considerably lengthened and refined 
in recent decades. In the chronological chapter, less reliance would today be placed on the evidence from the Philistine sites (pp. 107-9) as a secure terminus for cross-dating to the Aegean. Conversely, a new discovery of great potential importance was the excavation of part of a Middle Protogeometric Greek krater, in a context perhaps datable to around Iooo BC, at Tell Hadar on the Sea of Galilee. ${ }^{5}$ On the broader question of the duration of the Early Iron Age, a case has been made for down-dating the closing centuries of the Bronze Age by more than a century, which would reduce the interruption in the documented record; but it has been matched by a parallel proposal to bring down the dates of the end of the Geometric style and the Archaic period, which would leave a similar gap unfilled. ${ }^{6}$ Each case seems to me to rest on evidence rather weaker than that for the orthodox chronology; and scientific dating methods, which will eventually give a definitive answer, have so far acted to confirm the existence of a substantial lapse of time between the last datable constructions of the Bronze Age civilisations and the first undertakings of the reviving historical cultures.

From this point on, I think it will be preferable not to appraise the content chapter by chapter, but to address certain central theses put forward in $197 \mathrm{I}$, most of which have since given rise to extended debate. I begin, however, with an argument which subsequent scholarship has so far passed over in almost complete silence: it first arises in pp. $179-83$ of Chapter 4 , and is then discussed in a broader context in Chapter 7, pp. 383-6. This is the suggested parallel, and the more tentative hint of continuity, between the Middle Helladic and Early Iron Age cultures of mainland Greece. Here is an idea which seems to me to have gained considerably in strength with the passage of the years, particularly through the major extension of field-work in peripheral regions of the Mycenaean world like Phokis, Lokris and Aetolia. There, a picture is emerging of whole areas where the reflections of Mycenaean culture were faint and fleeting at best; and where as a result the material features of Middle Helladic times appear to merge directly and uninterruptedly into those of the post-Mycenaean period, which so closely resemble them. The implications of this continuity are far-reaching, and I plan to return to them in future publications. It is enough to say here that this new material offers not merely a strengthening of the evidence, but the potential for an explanation, for many of the material features, hitherto seen as revivals or regressive adaptations, of the Early Iron Age culture of the Greek mainland. 
The study of Early Iron Age cemeteries, and of burial generally, has been greatly enriched by new publications and syntheses, devoted to Attica (especially), to the Argolid, Euboea, Epirus, Crete and the far West. ${ }^{7}$ The new cemetery publications have, not surprisingly, added enormously to the volume of iron finds, as well as of pottery: three examples that stand out in this category, by no means only on grounds of size, are the partial publication of the array of cemeteries at Lefkandi in Euboea; of the first group of tombs from the huge cemetery at Pithekoussai on Ischia; and of the equally huge North Cemetery at Knossos. ${ }^{8}$ With the iron objects (though much less so with the pottery), the striking feature has been that the typological range has been so little extended: instead, the main effect has been greatly to enrich the existing categories of weapons, tools and jewellery.

At the same time, this access of new material leads naturally on to a more contentious issue, the hypothesis of a shortage of bronze, affecting important areas of Greece during the earlier part of the dark age, advanced in this book (Chapter 5, pp. 237-9). On the one hand, the new grave-finds have only served to reinforce the appearance of an overwhelming dominance of iron at this time; on the other, later study of evidence from other parts of the Mediterranean world has shown that some of the phenomena used to support the hypothesis, such as the intermittent use of iron to make fibulae, also occur outside Greece, in circumstances where there is little sign that access to bronze had been cut off. Here too it should be said that a quite different line of explanation has been advanced, to the effect that the much-increased deposition of iron in early tombs reflects, rather, the temporary prestige that iron enjoyed, and a certain social exclusiveness in access to its use.' Strict control over the necessary technical knowledge could still 'ration' the distribution of iron, so that even the widespread availability of iron ore is not a conclusive argument against this latter explanation; but it does have to be reconciled with the fact (reinforced by new analyses from Cyprus and elsewhere) that early iron objects show the invariable presence of carburisation and other techniques designed to ensure their practical effectiveness. In any case, neither the explanation based on the posited shortage of bronze, nor that of an exclusive exploitation of iron by a controlling élite, can be applied to more than a brief transitional phase: presently bronze objects return in a steady trickle and finally, by the later eighth century, in a flood. Nothing in all this has detracted from the view that the initial adoption of iron, what- 
ever the precise social circumstances of its occurrence in Greece, represents one of the major technological advances in human history. What it rather reveals is a profound difference of views about the nature of Greek society at the period in question. To this vexed question we should now turn.

The picture presented in my book was a strongly egalitarian one: see especially Chapter 7, pp. 380-3. Neither in the contents of the numerous graves, nor in the rarer surviving architecture and settlement-finds, could I detect any signs of marked social stratification. Since then, a number of scholars have found reason to conclude otherwise. The most important of such arguments is without doubt that first advanced by Ian Morris in his book of 1987 (cited in n. 7): that the surviving burial record, especially from Athens but probably more widely, is representative only of a select minority of the population. In other words, formal burial had itself become a privilege, not universally extended - specifically, not to poorer adult males, or to many women or children. The period of this exclusiveness extends, in Athens, from roughly the beginning of the Attic Protogeometric period to the end of the Middle Geometric, some 300 years on the orthodox chronology. This radical insight is supported by a wide range of arguments and I am in no doubt that it is soundly based. The implication is, to put it somewhat crudely, that my 'egalitarian' interpretation arose from applying an inappropriate standard of material wealth: the 'impoverished' burials of these centuries still represent something beyond the reach of the majority. But, obviously enough, this conclusion serves further to reinforce the impression that the overall level of disposable wealth was strikingly low. If it is objected that this poverty applies only to the provision of burial goods, which are a matter of cultural preference, then it is reasonable to ask for counter-evidence from other contexts.

Just such evidence has, in many opinions, been forthcoming from the site of Lefkandi. Not only has the progressive publication of the cemeteries here (see n. 8) revealed a recurrent pattern of fairly rich grave-goods, unmatched in any of the sites that I had studied, and calling into question the case for the isolation of Greece at this period (see pp. 246-9, 328, 368-80); but the discovery of the unique building at the Toumba site has also revealed architecture of a scale and pretension which has surprised everyone - and this at a date probably in the tenth century Bс. A preliminary account of this find was given in 1982 , and a full publication has since appeared. ${ }^{10}$ Its owners - or, in 
the excavators' opinion, the honorands of its construction - are reasonably identified in the couple buried, also with unique accoutrements, below its floor. As this last sentence implies, controversy has arisen over the purpose of the building, whether domestic or commemorative; but its architectural importance remains largely unaffected by that. Twice the size of any structure known from the Greek world within two centuries or more on either side of its date, it surely represents, together with a handful of the richest graves from Early Iron Age Greece, the very apex of the social pyramid. Yet some qualifications apply, parallel to those in the case of the reappraisal of early Greek burials. In its size and in the provision of a (timber) colonnade or veranda running most of the way round it, it stands out clearly from the pattern previously recognised; but in its materials and construction it does not. The apsidal plan and mud-brick walls, on a socle of uncut stones and reinforced by timber uprights, are entirely typical of the day: so is the roof, probably thatched, which had been at least partly laid when the whole structure was - perhaps deliberately - destroyed. While greatly extending the picture of the aspirations of the building practices of its time, it leaves the range of those practices largely unchanged. No more than its contemporaries was it a 'monumental' structure, in the sense of being built for durability. Its importance lies rather in the light it throws on the issue of social differentiation - and perhaps on the separate question of regional disparity.

A feature of the Lefkandi grave-goods which has already been alluded to is their geographical range of origins: for well over a century, from the date of the Toumba building down to the abandonment, around $825 \mathrm{BC}$, of the cemeteries so far excavated, grave after grave produces evidence of contact with a wide area of the Eastern Mediterranean. It is more likely than not that the carriers of these exotic goods were themselves Euboeans; but even if they were not Greeks at all, this would still be enough to show that Lefkandi was a regular calling-point for ships from much further east. This is an extremely important new finding, and it is not an entirely isolated one. At Kommos on the southern coast of Crete, a sequence of temples of nonGreek form has been excavated which, with some accompanying imports, point firmly in the direction of a Phoenician presence at the site. ${ }^{.1}$ Belief in the isolation of the entire Aegean world, even for the relatively short period for which I had posited it, can no longer be sustained.

Yet almost as striking is the fact that, after thirty further years of archae- 
ological discovery, the evidence of external contacts remains so clearly concentrated in geographical terms: indeed, the new finds serve to accentuate this. Even when we combine the more or less direct evidence of imports (and of the decidedly rarer exports outwards from the Aegean) with the much less secure arguments from the adoption of new practices which could have had an external inspiration, the list of regions affected remains fairly short: Attica, the Argolid, central Euboea, Thessaly, the central Cyclades, Crete and the south-western coast of Asia Minor. Some of these regions are represented by no more than one or two sites. As already remarked (above, p. 3), they share the common feature of possessing a seaboard on the Aegean itself. The greater part of the Greek peninsula, to the west and north-west, remains as unaffected as before.

So far, discussion has been largely confined to the discoveries made by recent excavation and to their interpretation. Something must be added about the results obtained by the much newer technique of intensive surface survey, which began to be widely applied in Greece about a decade after the appearance of the book. Quite large areas of the Greek landscape have now been covered by teams of field-walkers, searching for the traces of past activity, of all periods, left on the surface - in northern and central Greece, the Peloponnese and the islands. Several of these projects have already generated major publications. ${ }^{12}$ Their findings in respect of this period are strikingly concordant. Some thousands of 'sites', large and small, known and unknown, have been identified in what is today the open countryside; in many cases, they show several periods of activity or occupation, extending from the Palaeolithic to early modern times. Yet the Early Iron Age is one of a small number of periods - the earlier Neolithic, the Middle Bronze Age, the Early Byzantine period - whose traces are very seldom present. Broadly speaking, it is only in the larger settlements, often with occupation both in the Bronze Age and in historical times, where pottery or other remains datable to this time are found: even there, they are usually present in small quantities. This is a negative finding of direct importance. It suggests that the Early Iron Age population, such as it was, had not been scattered into isolated pockets across the landscape, but was nucleated, probably to a greater degree than before or after. Hitherto, it was possible to argue that the fugitive quality of Early Iron Age remains in the excavation record was the result of looking in the wrong locations: now, on the contrary, it seems that 
they are most likely to occur in just the kind of site which would be selected for excavation. The implications for the general level of population at this period are obvious: not only is the number of sites known to be in occupation remarkably low, as was already clear; but the quantity of material in the sites that were inhabited is nearly always overshadowed by that from the Bronze Age or the Archaic period.

There is a further debate whose light plays around the edges of all discussion of this period, but which has not yet been mentioned. This is the relationship between the modern archaeological concept of the 'dark age' on the one hand, and the world portrayed in the Homeric poems on the other.

My treatment of this issue (in Chapter 7, pp. 388-94 and 434-6) has been justly criticised for concentrating on physical features, to the exclusion of institutions. But it may be unnecessary to reopen this apparently unending debate here. In a study of periodisation in early Greek history, Ian Morris has written that, in the 1970s, 'there was a classic example of the paradigm shift ... with hardly any sustained debate in print, the archaeological model quietly swept the field. ${ }^{13}$ Whether or not one welcomes this outcome, it is hard to question its reality. There seems today to be an unspoken consensus that the Early Iron Age is as much the archaeologists' property, to be evaluated primarily in archaeological terms, as is, say, the Bronze Age something which I remember hearing openly contested in the 1960s. Even a chronologically late phenomenon like the incidence of cult at prehistoric tombs, briefly treated in this book (Chapter 4, pp. 192-4), which belongs close to the end of this period and has clear implications for Greek religion of historical times, has since given rise to an extensive literature, predominantly of an archaeological kind; $;^{14}$ and the same can be said of the archaeological study, on a scale much larger still, of the early Greek sanctuary-finds.

It will by now be clear what the main changes in emphasis would have been, had a full rewriting of this book proved possible. There would have been less emphasis on isolation, but even greater on continuity from the past, especially from the pre-Mycenaean age. As a consequence of this last point, there would have been a detectable shift in the balance of emphasis between different regions of Greece, with closer attention paid to the culture of the less advanced regions which may represent the norm of responses to the breakdown of Mycenaean civilisation, and a background against which 
the few prominent sites stand out in contrast. Again as a consequence, there would have been even more stress on regional differences. There would have been major concessions on the stratification of Greek society, but based on the archaeological finds and their interpretation, not on any revision of views as to the historical applicability of the Homeric evidence.

My over-riding reason for not attempting the task is, however, a feeling that it is time for study and discussion to advance beyond the level on which the book was written. It is now clear that the 'dark age', at any rate in terms of the simple lapse of time, will not go away. It must be either radically reinterpreted, or explained as it is. For those archaeologists who believe in its current interpretation, one urgent task (as I argued in 1987 - see n. I) is to explain its long duration: to throw light on the process - often repeated in history - whereby a culture and a people with major attainments behind them, of a highly visible kind archaeologically, and with even more obvious ones ahead of them, were content for some centuries to pass during which there would not be, materially speaking, anything comparable to show. There should also be greater stress on the search for positive aspects of the choices made at this time: adaptation, physical mobility, economic change and the mere adjustment of social priorities need to be measured against decline, deprivation and depopulation. These are surely the directions in which research must now turn, and I welcome the signs that it is beginning to do so. 


\section{Notes}

I] The greater part of the text was in fact written in 1968. The Rumanian edition, Grecia: Epocii Intunecate (trans. M. Gramatopol, Bucharest, 1994) appeared without alteration to the main text. My nearest approaches to a reassessment of the whole field have been a short paper 'The Greek Early Iron Age: A Reappraisal', in Dialogues d'Histoire ancienne 9 (1983), 73-86; and Chapter 6 of my book An Archaeology of Greece (Berkeley and Los Angeles, 1987), 'The Early Iron Age of Greece' (pp. 170-210).

2] It is significant that works by other scholars, treating the period (or a large part of it) at a similar level of detail, have tended to die away in recent years: see notably J. Bouzek's Homerisches Griechenland (Prague, 1969), which actually antedated my book but was not available in the West in time to be assimilated, either in my own work or in that of V. R.

d'A. Desborough, The Greek Dark Ages (London, 1972); J. N. Coldstream, Geometric Greece (London, 1977); C. T. Syriopoulos, I metabatiki hróni: apó tís Mikinaikis eis tin Arhaikin periodon, 2200-700 p.Khr. (Athens, 1983). Presently began the appearance of composite volumes (which still continue): edited by $\mathrm{S}$. Dcger-Jalkotzy, Griechenland, die Ägäis und die Levante während der 'Dark Ages' (Vienna, I983); by R. Hägg, The Greek
Renaissance of the Eighth Century $B C$ (Stockholm, 1983); by D. Musti, La Transizione dal miceneo all'alto archaico (Rome, I99I); and by S. Langdon, New Light on a Dark Age: Exploring the Culture of Geometric Greece (Columbia, MO/London, 1997). The latter end of the period is extensively treated in a triple number of Annuario, 59-6I (I98I-3), devoted to the Conference 'Grecia, Italia e Sicilia nell' VIII e VII secolo a.c.'. Later single-author treatments have been more summary: W. D. E. Coulson, The Greek Dark Ages: A Review of the Evidence and Suggestions for Future Research (Athens, 1990); R. Osborne, Greece in the Making, 1200-479 BC (London/New York, 1996). A volume on this period by Dr Oliver Dickinson (as a sequel to his The Aegean Bronze Age (Cambridge, 1994)) is promised for the near future.

3] Most memorably, by J. K. Papadopoulos in Journal of Mediterranean Archaeology 6 (1993), pp. 196-7: 'Greek civilization ... would certainly be better served if the spectre of the Dark Age, a phantom that has haunted the "musty confines of Cambridge" ... for too long, is finally laid to rest.'

4] A point well brought out by the table in n. I5 (p. 147I) of A. Schnapp's review article, Annales: Économies, Sociétés, Civilisations 29 (1974), $1465-76$.

5] For a preliminary notice, see A. Mazar in V. Karageorghis (ed.), Cyprus in the Eleventh Century BC (Nicosia, 1994), at p. 48 .

6] See, respectively, P. James and others, Centuries of Darkness: A Challenge to the Conventional Chronology of Old World Archaeology (London, I99I); and E. D. Francis and M. Vickers, 'Greek Geo- 
metric Pottery at Hama and its Implications for Near Eastern Chronology', Levant 17 (I985), I3I-8, one of a series of articles by the same authors.

7] Note especially, among others too numerous to list here, G. Krause, Untersuchungen zu den ältesten Nekropolen am Eridanos in Athen (Hamburg, 1975); I. Morris, Burial and Ancient Society (Cambridge, 1987); J. Whitley, Style and Society: The Changing Face of a Pre-Literate Society, 2100-700 BC (Cambridge, 199I); R. Hägg, Die Gräber der Argolis in submykenischer, protogeometrischer und geometrischer Zeit $\mathbf{I}$ : Lage und Form der Gräber (Uppsala, I974); P. Courbin, Tombes géométriques d'Argos I (Paris, 1974); I. Vokotopoulou, Vitsa: tá nekrotafeía mías Molossikis komís $\mathrm{I}-3$ (Athens, 1986); and the three works mentioned in the next note.

8] M. R. Popham and others (ed), Lefkandi i: The Iron Age Settlement and Cemeteries (London, 1979-80); Lefkandi iii: The Early Iron Age Cemetery at Toumba: Plates (London, 1996); G. Buchner and D. Ridgway, Pithekoussai I (Rome, I993); J. N. Coldstream and H. W. Catling (eds), Knossos North Cemetery: Early Greek tombs I-4 (London, 1996).

9] Ian Morris, 'Circulation, Deposition and the Formation of the Greek Iron Age', Man 24 (1989), pp. 502-19.

Io] M. R. Popham, P. G. Calligas and L. H. Sackett (eds), Lefkandi ii: The Protogeometric Building at Toumba: I, The Pottery, with R. W. V. Catling and I. S.

Lemos (London, 1990); 2, The Excavation, Architecture and Finds, with J. Coulton and
H. W. Catling (London, 1993), especially pp. 49-59, 97-IOI on the interpretation of the building.

II] For a convenient summary, see J. W. Shaw, 'Phoenicians in Southern Crete', AJA 93 (1989), pp. 165-83.

I2] Notably, J. F. Cherry, J. L. Davis and E. Mantsourani, Archaeology as LongTerm History: Northern Keos in the Cycladic Islands (Los Angeles, 199I), especially pp. 245-7; A. Rizakis (ed.), Paysages d'Achaie: le bassin du Peiros et la plaine occidentale (Athens, 1992), esp. pp. 167-8; H. Lohmann, Atene: Forschungen zur Siedlungs- und Wirtschaftsstruktur des klassischen Attika (Cologne/Weimar/Vienna 1993), esp. p. 36; M. H. Jameson, C. N. Runnels and T. H. van Andel, $A$ Greek Countryside: The Southern Argolid from Prehistory to the Present Day (Stanford, I994), esp. pp. 372-4; W. G. Cavanagh and others, The Lakonia Survey ii: The Archaeological sata (London, 1996) (note the hiatus between Chapters I3 and I4); C. B. Mee and H. Forbes (eds), A Rough and Rocky Place: The Landscape and Settlement of the Methana Peninsula, Greece (Liverpool, 1997), esp. p. 57.

I3] I. Morris, 'Periodization and the Heroes', in M. Golden and P. Toohey (eds), Inventing Ancient Culture: Historicism, Periodization and the Ancient World (London/New York, 1997), pp. 96-131, at p. I23.

I4] See, most comprehensively, C. Antonaccio, An Archaeology of Ancestors: Tomb Cult and Hero Cult in Early Greece (Lanham, MD, 1995). 